\title{
Visualization of the Bainite Fine Structure Using EBSD and Euller Angles
}

\section{Yu.V. Yudin, A.A. Kuklina, M.V. Maisuradze, and M.S. Karabanalov}

Russia, Yekaterinburg, Mira Str., 19, Ural Federal University

\section{Abstract}

The electron backscatter diffraction method (EBSD) is widely used to study crystallographic orientational relationships of the steel microstructure constituents including bainite. Nevertheless the fine structure of bainite (subunits, plates) is not investigated by this method. In this paper we propose a technique for visualizing of the structure of a bainitic steel near-surface layer using the values of Euler angles obtained by EBSD method. A three-dimensional picture of the bainite fine structure of the HY-TUF steel obtained by the proposed technique is in satisfactory agreement with the data obtained earlier by the atomic force microscopy.

Corresponding Author:

Yu.V. Yudin

yudinuv@rambler.ru

Received: 25 February 2019

Accepted: 9 April 2019

Published: 15 April 2019

Publishing services provided by Knowledge E

(c) Yu.V. Yudin et al. This article is distributed under the terms of the Creative Commons

Attribution License, which permits unrestricted use and redistribution provided that the original author and source are credited.

Selection and Peer-review under the responsibility of The Ural school-seminar of metal scientists-young researchers Conference Committee.
Keywords: steel; bainite; fine structure; plates; EBSD; Euler angles.

\section{Intorduction}

Recently the numerous studies of the bainite microstructure in various high-strength alloyed steels were carried out [1 - 3].This is due to the fact that the optimal combination of high strength and ductility of steel is determined by the fine structure of bainite the thickness of the bainite plates and subunits, the dimensions and morphology of the residual austenite layers etc. [4 - 6]. However the optical microscopy has some major limitations for the investigation of the fine structure of steel and the development of new concepts about the morphology at the level of nanometers [7]. The data on the fine structure of metals and the information about the crystallographic orientations can be obtained by the electron backscatter diffraction method (EBSD) [8, 9]. By the way some of the possibilities of EBSD analysis are not yet fully understood. For example, the use of Euler angles for the microstructure characterization is not covered in the available literature sources. Nevertheless, this matter is of great scientific interest since it can contribute to the determination of both qualitative and quantitative relations between the fine structure of bainite and the values of mechanical properties (strength and toughness) [10].

\section{S OPEN ACCESS}




\section{Experimental}

The studied HY-TUF steel is widely used in aerospace engineering and heavy machinery for manufacturing of the heavy loaded parts such as axles, shafts, engine parts etc. [11, 12]. The steel under consideration [13] was produced using an electric arc furnace with graphite electrodes in the industrial conditions of the metallurgical plant. The ingots of the HY-TUF steel (4 tons) were homogenized in the industrial pit furnace at a temperature of $1200 . . .1250{ }^{\circ} \mathrm{C}$ for $12 . .15 \mathrm{~h}$. The final product was the hot rolled annealed round steel bar with a diameter of $140 \mathrm{~mm}$.

The samples of the studied HY-TUF steel $(10 \times 10 \times 5 \mathrm{~mm})$ were heat treated according to the following sequence: heating in a laboratory furnace up to $925^{\circ} \mathrm{C}, 40 \mathrm{~min}$., isothermal quenching in molten salt bath $\left(50 \% \mathrm{KNO}_{3}+50 \% \mathrm{NaNO}_{3}\right)$ at a bainitic transformation temperature of $370 \ldots 430{ }^{\circ} \mathrm{C}$. The isothermal holding time was $2 \mathrm{~h}$, which was enough to form the maximum fraction of bainite in the HY-TUF steel: 0,85 for transformation temperature $370^{\circ} \mathrm{C}$ and 0,75 for $430^{\circ} \mathrm{C}[14]$. The heat treated samples were ground and polished using a suspension of colloidal silicon.

The study of the fine structure of bainite was carried out using Zeiss Auriga Cross Beam electron-ion microscope with a software for recording and analyzing of the electron back scatter diffraction patterns Nordlys HKL Channel ${ }^{\circledR}$. The construction of a three-dimensional image of the bainite fine structure was carried out using the "Surfer 13 " software.

\section{Results and Discussion}

The orientation maps (Fig. 1, a) of the HY-TUF steel bainite microstructure obtained by the electron backscatter diffraction (EBSD) show a multi-oriented crystallographic structure with the limited areas (probably the former austenite grains). The size of such areas is $30 . .60 \mu \mathrm{m}$. Within the limited areas (i.e. within one former austenite grain) the zones with alternating crystallographic orientations are revealed. These zones are characterized by a complex topology of bainite. The dimension of the bainite zones with the alternating orientations is from $8 \times 1,5$ to $10 \times 5 \mu \mathrm{m}$ (Fig. 1, b). The orientation maps do not allow investigation of the finer structure of bainite (the plates that make up the package). The use of the values of Euler angles of each scanned elementary area on the sample surface can solve this problem.

The following approach was used to obtain the relief of the near surface layer using Euler angles. Imagine an elementary area scanned by an electron microscope, for which 


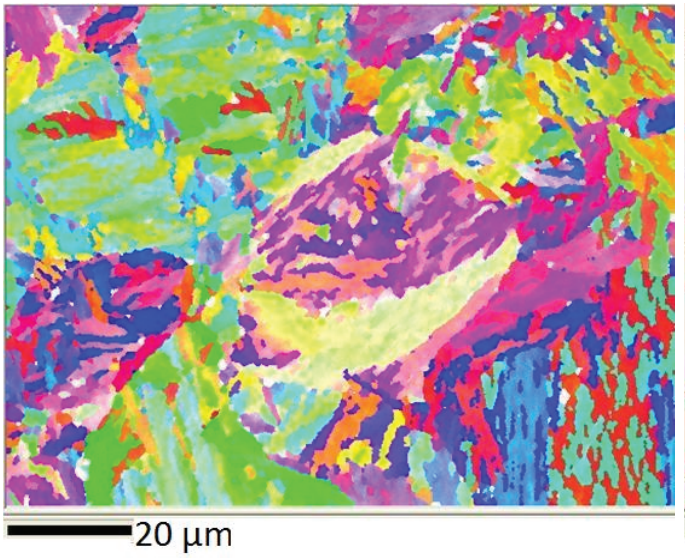

a

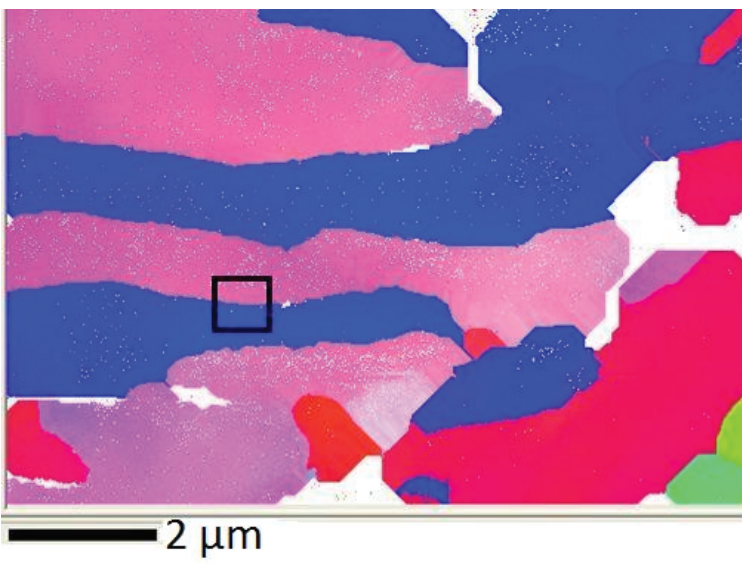

$\mathrm{b}$

Figure 1: Orientation maps of the bainite microstructure obtained by electron backscatter diffraction (EBSD) for the HY-TUF steel austempered at the temperature $370{ }^{\circ} \mathrm{C}$.

the values of Euler angles are known (Fig. 2).These data are used to determine the coefficients of the plane equation of this area in coordinate system of the electron microscope. A perpendicular to the plane of an elementary area intersects the virtual screen, located at a distance $\mathrm{D}_{0}$ parallel to elementary areas of size $\mathrm{m} \times \mathrm{n}$ (for example $400 \times 500 \mathrm{~nm}$ ), at a point with coordinates $\mathrm{x}_{1 e}, \mathrm{x}_{2 e}, \mathrm{D}_{0}$. When an elementary area is turned from the position parallel to the virtual screen, the deviation $Z_{0}$ from the straight perpendicular reflection is observed on it (an elementary area parallel to the virtual screen is shown by dotted line). The coordinates of the deviation point on the virtual screen in this case is $\mathrm{x}_{2 e}, \mathrm{y}_{2 e}, \mathrm{D}_{0}$. The obtained distance $\mathrm{Z}_{i}$ is related to the coordinates of the center of an elementary area $\mathrm{x}_{0}, \mathrm{y}_{0}$. Then the distances $\mathrm{Z}_{i}$ are determined for the whole considered surface of the sample and a three-dimensional image of the nearsurface relief of the studied microstructure may be plotted.

The proposed method was implemented to obtain the 3D image of the near-surface bainite microstructure of the HY-TUF steel austempered at the temperature of $370{ }^{\circ} \mathrm{C}$ (Fig. 3, a). The image presents the rows of the "hills" and the "valleys" which characterize the bainite plates. The features of the bainite morphology were estimated quantitatively using the 3D model of the near-surface relief of the HY-TUF steel fine structure. Fig. 3, b shows the integral distributions of the distances between the "hills" on the 3D images of the near-surface relief obtained for the samples austempered at the temperatures of 370 and $430{ }^{\circ} \mathrm{C}$. The number of the measured distances was $100 . . .120$ measurements. There is an obvious dependence of the distance between the rows of the "hills" and the "valleys" on the austempering temperature: the decrease of the temperature from 430 to $370{ }^{\circ} \mathrm{C}$ leads to the decrease of the measured distance between the rows from 24 to $13 \mathrm{~nm}$. 


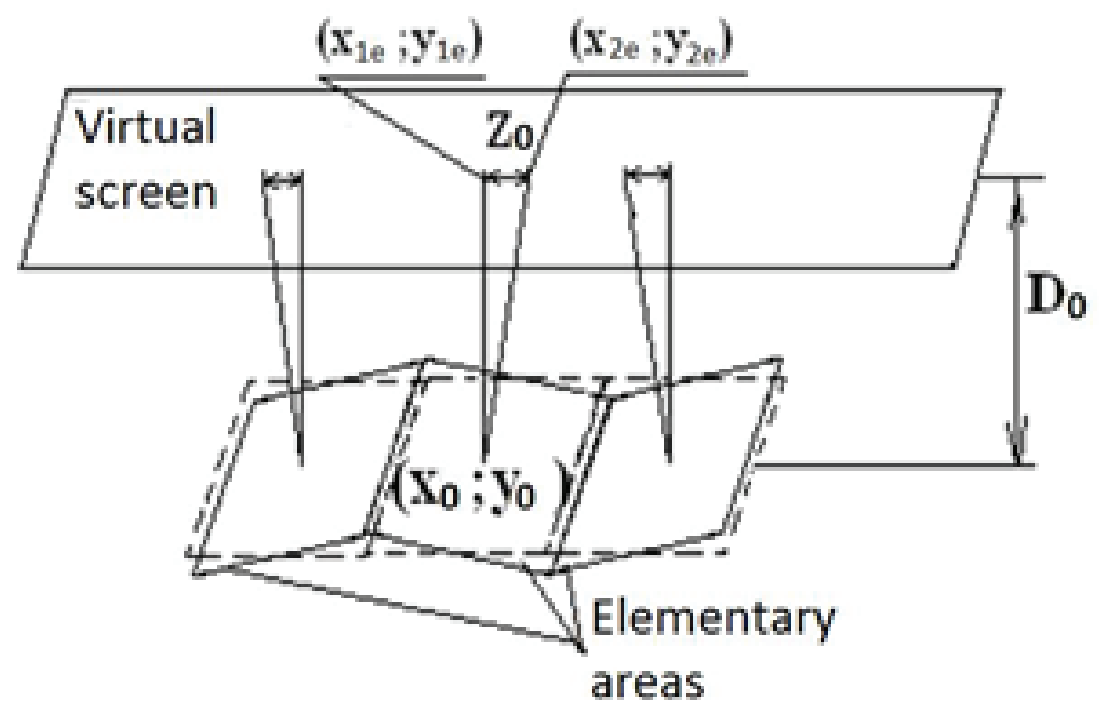

Figure 2: Diagram of the formation of the image of the near-surface microstructure using the EBSD method.

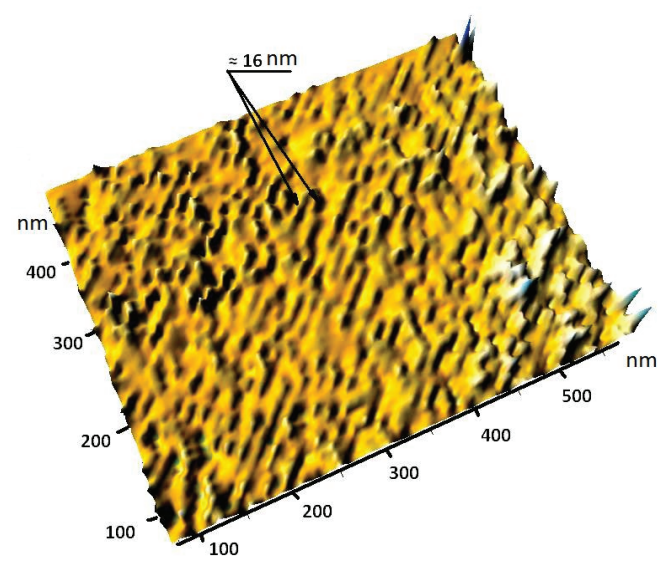

a

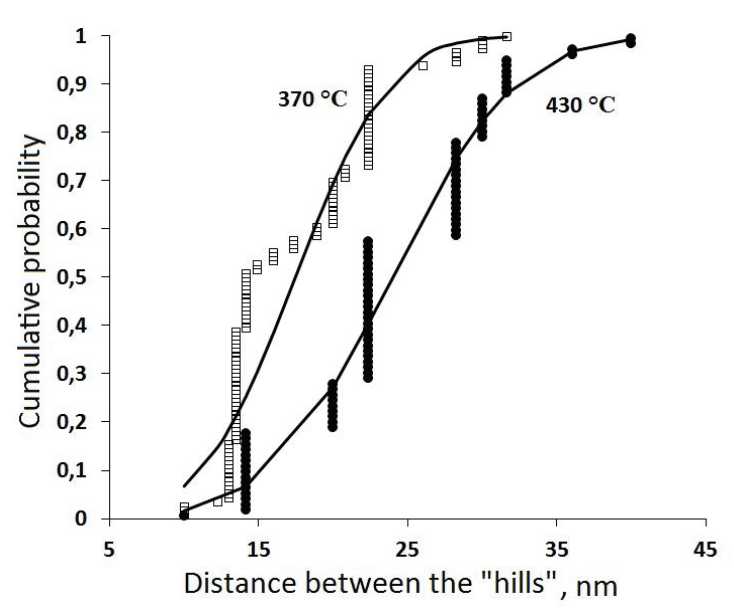

$\mathrm{b}$

Figure 3: The near-surface relief of the bainite microstructure of the HY-TUF steel austempered at the temperature of $370{ }^{\circ} \mathrm{C}(\mathrm{a})$ and the corresponding integral distribution of the distances between the "hills" and the "valleys" (b) for the austempering temperatures 370 and $430^{\circ} \mathrm{C}$ (the solid line is the normal distribution).

To determine the real distance between the bainite plates, the distance between the "hills" and the "valleys" measured on a 3D image should be doubled. This is related to the feature of the applied visualization method: the identical reflections on the virtual screen are generated from both the "hills" and the "valleys" on the real surface. This phenomenon is illustrated by an example of a surface having a periodic relief (sinusoidal, see Fig. 4). The rays of light hit this surface. In this case the strictly perpendicular reflections will be projected onto the virtual screen from both the "hills" and the "valleys". Therefore, in order to determine the real period of the sinusoidal surface, the distance between the reflections visible on the virtual screen should be multiplied by 2 . So, considering this 
feature of the image formation, the real distance between the bainite "peaks" of the HYTUF steel microstructure decreases from 48 to $26 \mathrm{~nm}$ as the transformation temperature decreases from 430 to $370{ }^{\circ} \mathrm{C}$.

In the previous work [14] the surface relief of the austempered HY-TUF steel was studied using the atomic force microscopy (Fig. 5). The surface relief determined by the atomic force microscope is obviously similar to the one obtained using the proposed EBSD-based method (Fig. 3, a). Fig. 6 shows the integral distributions of the distances between the rows of the etched bainite plates obtained using an atomic force microscope. The decrease of the austempering temperature from 450 to $330{ }^{\circ} \mathrm{C}$ led to the decrease of the median thickness of the bainite plates from 75 to $20 \mathrm{~nm}$. Note that for the austempering temperature 370 and $430{ }^{\circ} \mathrm{C}$ the thickness of the bainite plates was 35 and $45 \mathrm{~nm}$, respectively, according to the atomic force microscopy. This closely agrees with the data obtained in the present paper.

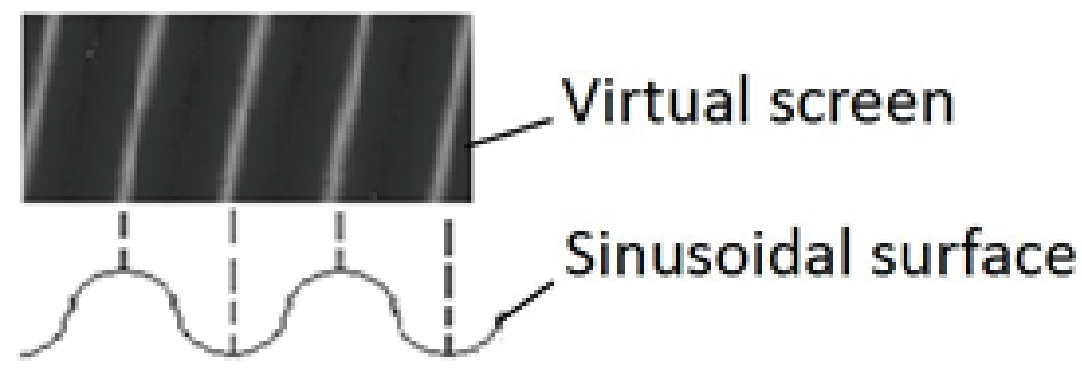

Figure 4: The formation of an image of the surface with sinusoidal relief on a virtual screen.

The visualization of the near-surface bainitic structure of the HY-TUF steel was also performed for the interface of two differently oriented areas (marked by the black square on Fig. 1, b). The orientation of the rows of the bainite plates in differently oriented areas varies significantly (Fig. 7). Between the areas with different orientations there is a highangle boundary with a misorientation angle of $30^{\circ}$.

\section{Summary}

The method of visualization of the near-surface microstructure of steel using the Euler angles determined by EBSD is proposed. The thickness of the bainite plates in the HYTUF steel decreases from 48 to $26 \mathrm{~nm}$ when the austempering temperature decreases from 430 to $370{ }^{\circ} \mathrm{C}$. This closely agrees with the data obtained earlier by the atomic force microscopy (45 and $35 \mathrm{~nm}$ ). The orientation of the rows of the bainite plates in 


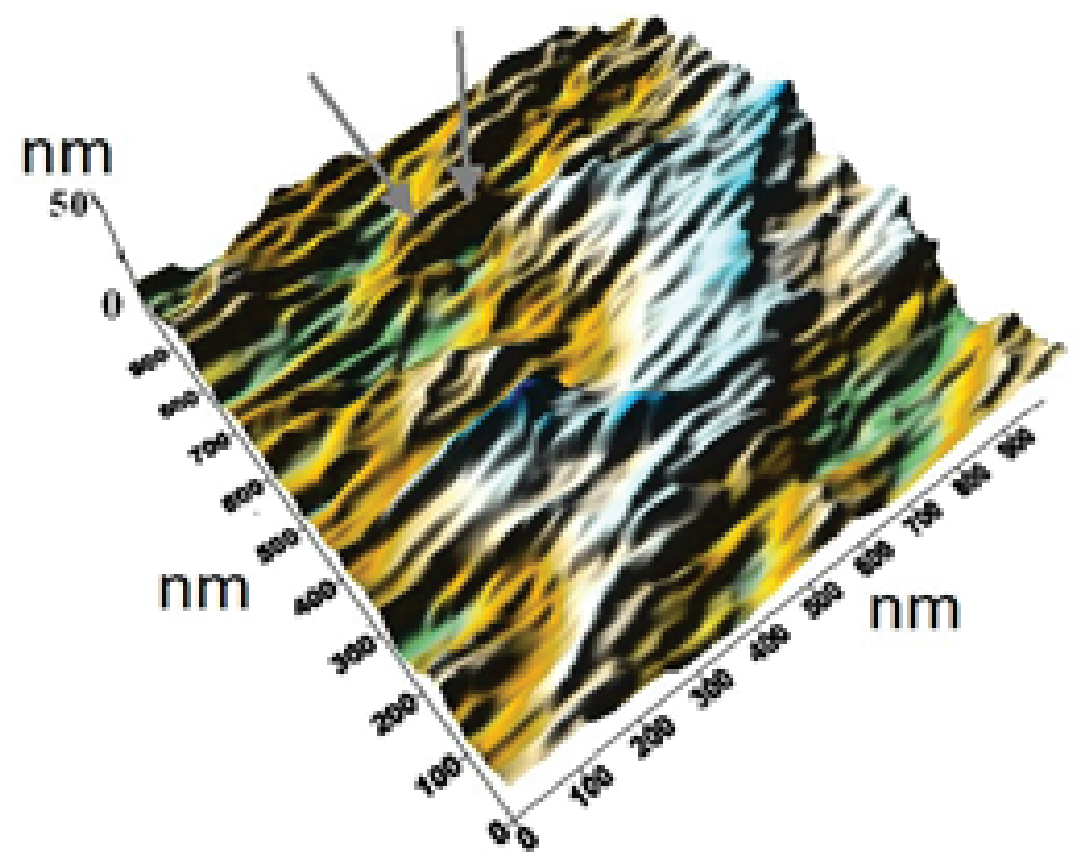

Figure 5: The surface relief of the bainite microstructure obtained by the atomic force microscopy for the HY-TUF steel austempered at the temperature of $370{ }^{\circ} \mathrm{C}$ (the bainite plates are shown by arrows) [14].

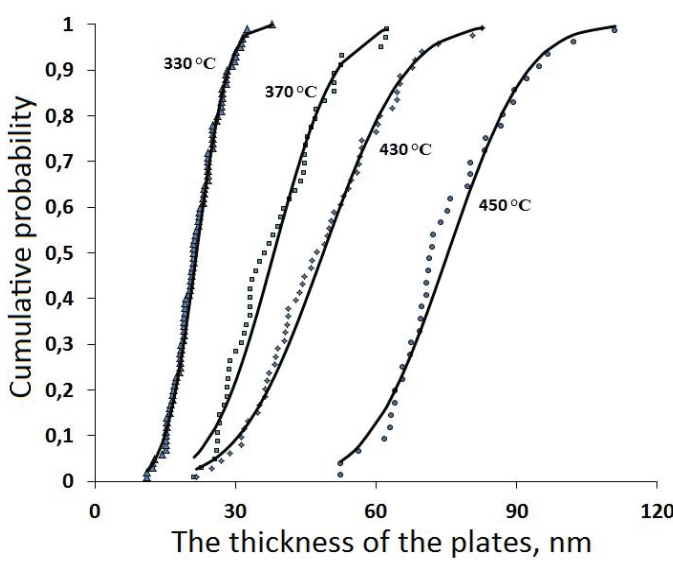

a

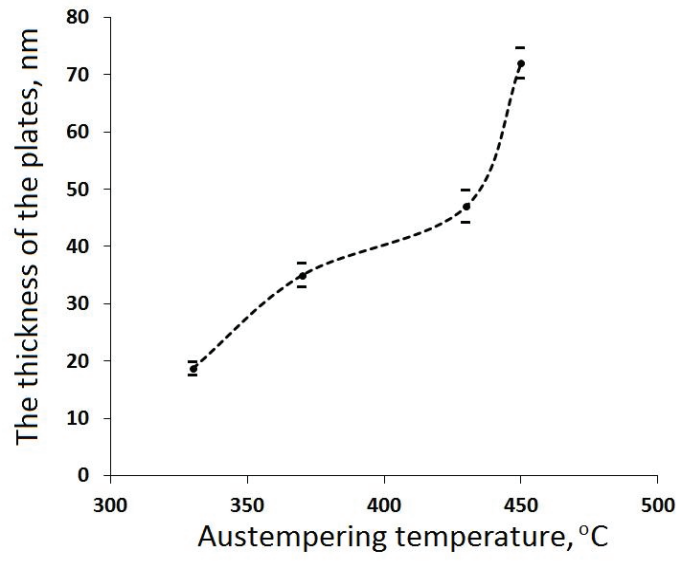

$\mathrm{b}$

Figure 6: Integral distribution of the thickness of the bainite plates of the HY-TUF steel (a) (solid line is the normal distribution) and the dependence of the median thickness of the bainite plates on the austempering temperature (b).

differently oriented areas is different. This depicts the specific crystallographic structure of the bainite. 


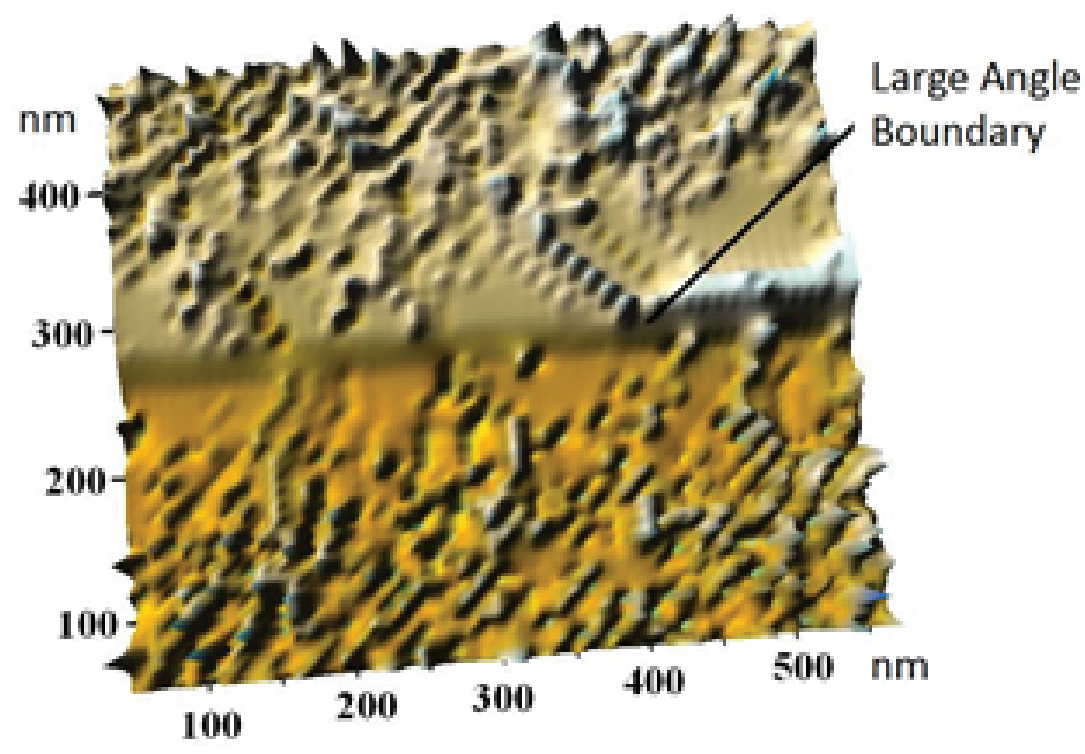

Figure 7: The relief of the microstructure of the HY-TUF steel near the boundaryr of two differently oriented areas (austempering temperature $370{ }^{\circ} \mathrm{C}$ ).

\section{Acknowledgements}

The work was supported by the Russian Federation Ministry of Education and Science (project № 11.1465.2014/K) and the Russian Federation Government Act № 211, contract №02.A03.21.0006.

The work was carried out using the laboratory equipment "Structural methods of analysis and properties of materials and nanomaterials" of the Center of Ural Federal University.

\section{References}

[1] Y.X. Zhou, X.T. Song, J.W. Liang, Y.F. Shen, R.D.K. Misra, Innovative processing of obtaining nanostructured bainite with high strength - high ductility combination in low-carbon-medium-Mn steel: Process-structure-property relationship, Mat. Sci. Eng. A. 718 (2018) 267-276.

[2] Q. Liu, X. Zhao, X. Zhang, H. Wang, Effect of cooling temperature field on formation of shelf-like bainite in high carbon silicon steel, Mat. Sci. Eng. A. 720 (2018) 176-179.

[3] M. Soliman, H. Palkowski, Development of the low temperature bainite, Arch. Civil Mech. Eng. 16 (2016) 403-412.

[4] S.M.C. van Bohemen, Exploring the correlation between the austenite yield strength and the bainite lath thickness, Mat. Sci. Eng. A. 731 (2018) 119-123. 
[5] A. Kumar, A. Singh, Toughness dependence of nano-bainite on phase fraction and morphology, Mat. Sci. Eng. A. 729 (2018) 439-443.

[6] S.H. He, B.B. He, K.Y. Zhu, M.X. Huang, On the correlation among dislocation density, lath thickness and yield stress of bainite, Acta Mater. 135 (2017) 382-389.

[7] X. Li. A. Ramazani, U. Prahl, W. Bleck, Quantification of complex-phase steel microstructure by using combined EBSD and EPMA measurements, Mater. Char. 142 (2018) 179-186.

[8] T.B. Britton, J. Jiang, Y. Guo, Tutorial: Crystal orientations and EBSD. Or which way is up? Mater. Char. 117 (2016) 113-126.

[9] L. Morales-Rivas, F. Archie, S. Zaefferer, M. Benito-Alfonso, S. Tsai, J. Yang, D. Raabe, C. Garcia-Mateo, F.G. Caballero, Crystallographic examination of the interaction between texture evolution, mechanically induced martensitic transformation and twinning in nanostructured bainite, J. Alloys Comp. 752 (2018) 505-519.

[10] P.P. Suikkanen, C. Cayron, A.J. De Ardo, L.P. Karjalainen, Crystallographic Analysis of Isothermally Transformed Bainite in 0.2C-2.0Mn-1.5Si-0.6Cr Steel Using EBSD, Mat. Sci. Tech. 29 (2013) 359-366.

[11] M.J. Leap, J. Rankin, J. Harrison, L. Hackel, J. Nemeth, J. Candela, Effects of laser peening on fatigue life in an arrestment hook shank application for Naval aircraft, Int. J. Fatigue. 33 (2011) 788-799.

[12] T.L. Mackay, B.J. Alperin, D.D. Bhatt, Near threshold fatigue crack propagation of several high strength steels, Eng. Fract. Mech. 18 (1983) 403-416.

[13] M.V. Maisuradze, M.A. Ryzhkov, Yu.V. Yudin, A.A. Kuklina, Transformations of supercooled austenite in a promising high-strength steel grade under continuous cooling conditions, Met. Sci. Heat Treat. 59 (2017) 486-490.

[14] Yu.V. Yudin, M.V. Maisuradze, A.A. Kuklina, Investigation of the bainite microstructure of the HY-TUF steel by the atomic force microscopy, Met. Term. Obr. Metal. 7 (2018) 16-20 (in Russian). 